\title{
COMPARISON OF THE ANTERIOR PITUITARY-ADRENAL CORTICAL STIMULATING EFFECT OF U.S.P. EPI- NEPHRINE, SYNTHETIC L-EPINEPHRINE, AND NOR-EPINEPHRINE ${ }^{1}$
}

\author{
BY LEONARD L. MADISON \\ (From the Department of Medicine, Southwestern Medical School of the University of Texas, \\ and the Department of Medicine of the Veterans Administration Hospital, \\ Dallas, Texas)
}

(Submitted for publication December 16, 1949; accepted, March 6, 1950)

The recent demonstration of the dramatic therapeutic effectiveness of the adrenal 11,17-oxysteroids (Compound $\mathrm{E}$ of Kendall) in the therapy of rheumatoid arthritis, rheumatic fever, and lupus erythematosus has lent great impetus to the study of the role of the adrenal cortex in these mesenchymal diseases, and to the search for new methods of stimulating the adrenal to produce endogenously these therapeutic agents in greater abundance (1-3). The wide variety of stimuli capable of producing an "alarm reaction" are all attended by one common factor, the stimulation of the autonomic nervous system with the consequent release of epinephrine (4). That epinephrine is capable of increasing pituitary secretion of adrenocorticotrophic hormone $(\mathrm{ACTH})$, which, in the presence of normal adrenals, results in augmented adrenal cortical activity has been demonstrated in animals (4) and in man (3).

Following the administration of ACTH to patients with normal adrenal glands a characteristic pattern of hematological changes occurs $(5,6)$. These alterations include a decrease in circulating lymphocytes and eosinophils, the latter more pronounced than the former, and appear to be the result of an increased secretion of 11,17-oxysteroids by the adrenal cortex $(5,6)$. The eosinopenic effect of epinephrine, dependent on the integrity of the anterior pituitary and adrenal cortex, has been utilized by Thorn and his associates (3) in a screening test for pituitary ACTH and adrenal cortical function. These investigators have also demonstrated that the chronic administration of small doses of epinephrine to patients augments

\footnotetext{
1 Published with permission of the Chief Medical Director, Veterans Administration, who assumes no responsibility for the opinions expressed or conclusions drawn by the authors.
}

adrenal cortical steroid hormone production with resultant eosinopenia and increased urinary 11oxysteroid and 17-ketosteroid excretion.

Although long suspected, it has only recently been proven that the adrenal medulla secretes two hormones, epinephrine and its non-methylated analogue, nor-epinephrine (arterenol, 1- [3, 4dehydroxyphenyl] 2-aminoethanol) $(7,8)$. Assays on U. S. P. epinephrine reference standards, and U. S. P. commercial epinephrine revealed a nor-epinephrine content varying from 10 to $35 \%$, the average being $15 \%$ (7-9). The present study was undertaken to determine which of the medullary hormones in U. S. P. commercial epinephrine is responsible for the eosinopenia secondary to anterior pituitary-adrenal cortical stimulation. The percentage drop in total circulating eosinophils is the most sensitive hematological measure of increased 11,17 -oxysteroid secretion by the cortical cells $(5,6,10)$, and was therefore utilized as the criterion in this study.

\section{METHOD}

Fifteen normal male subjects were used. After a 12 hour fast a basal eosinophil count was done and the subject given, on different days, $0.3 \mathrm{cc}$. of $1: 1,000$ (300 $\mu \mathrm{g}$.) U. S. P. epinephrine, nor-epinephrine (Winthrop), synthetic L-epinephrine (Winthrop), and saline as a control. Four hours later a repeat count was made. This period of time was chosen because maximum eosinopenic effect occurs then $(5,10)$. Food was withheld for the four hours since it has been shown that an ordinary meal may decrease the eosinophil count (11).

Total circulating eosinophil counts were done on freshly drawn oxalated blood by the chamber technic $(10,12,13)$. Heparin was not used because it is known to cause, in vitro, dissolution and agglutination of leukocytes within one hour $(14,15)$. Two standard white blood cell pipettes were used for each count. These same pipettes were again used for the repeat count, four hours later, in order to reduce the error of the method. The 
pipettes were filled to the 0.5 mark and diluted to the 11 mark with a special diluent $(0.1 \mathrm{Gm}$. Phloxin B, $100 \mathrm{cc}$. propylene glycol, $100 \mathrm{cc}$. distilled water) $(12,16)$. After 12 minutes, the pipette was shaken vigorously for two minutes and one side of a Levy chamber (16 sq. mm and $0.2 \mathrm{~mm}$ deep) was filled. The pipette was again shaken and the other side of the counting chamber loaded. The identical procedure was repeated with the second pipette. After allowing three to five minutes for the cells to settle, the eosinophils in each chamber were counted. The average of four chambers multiplied by 6.25 gives the eosinophils per $\mathrm{mm}^{3}$. With this diluent, the leukocytes remain colorless save for the eosinophils which stain a bright red, or, if a blue filter is used, a purplish red. After the basal and the four hour counts were made, the percentage change was computed since this provides the most clear cut evidence of change regardless of the initial magnitude of the eosinophil count $(5,6,10)$. The standard deviation of this method is 7.76 cells or $3.47 \%$.

\section{RESULTS}

The results are graphically represented in Figure 1. The mean fall in total circulating eosinophils after U. S. P. epinephrine is $54.9 \%$, with

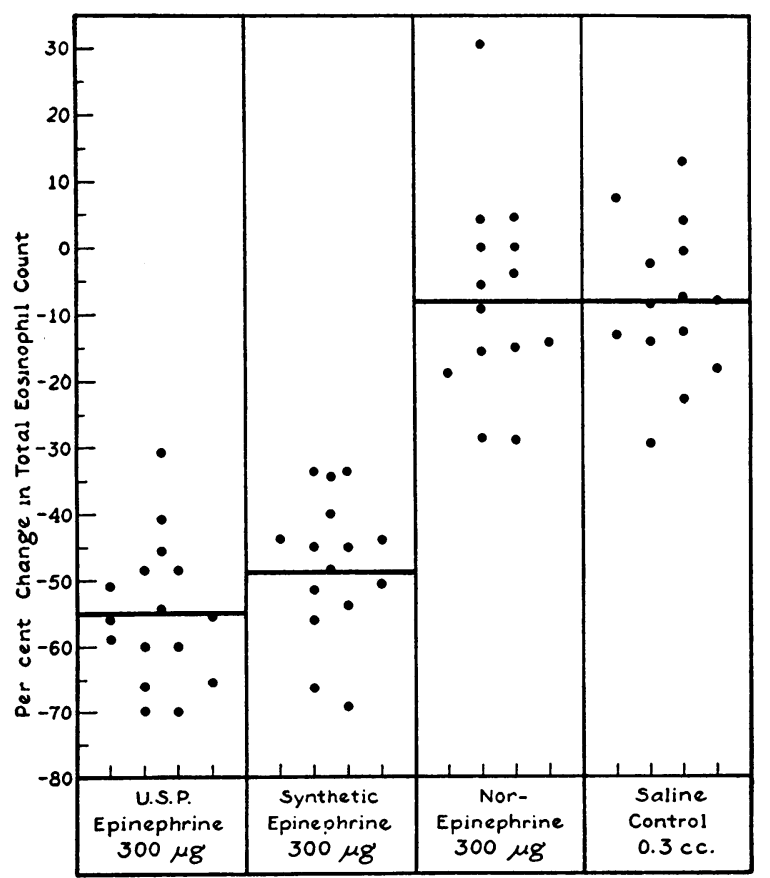

Fig. 1. Comparison of the Change in Total Circulating Eosinophils, Expressed as Per cent Change from Basal Eosinophil Count Four Hours After the Subcutaneous InJection of $300 \mu \mathrm{G}$. of U. S. P. EPINEPhrine, Synthetic L-Epinephrine, Nor-Epinephrine and Saline Control

Each dot represents an individual test. Heavy horizontal lines indicate mean fall for each group. a range of -32 to $-70 \%$, all but one falling more than $40 \%$. After synthetic L-epinephrine, the average decline is $47.2 \%$, with a range of -33 to - 69.7\%, all but three falling more than $40 \%$. After nor-epinephrine the mean decline is $8.2 \%$, with a range of +31 to $-29 \%$, and after saline the mean fall is $8.35 \%$, with an almost identical range.

This indicates that the anterior pituitary-adrenal cortical stimulating effect of U. S. P. epinephrine, measured by its eosinopenic action, is attendant on its L-epinephrine content and not on the nor-epinephrine which is present.

\section{COMMENTS}

The pharmacological differences between the naturally occurring hormones of the adrenal medulla, epinephrine and nor-epinephrine, have been stressed by several investigators $(7,17-19)$. The former, within physiological range, is an overall vasodilator, the increase in blood pressure being secondary to increased cardiac output. Nor-epinephrine is an overall vasoconstrictor with little, if any, effect on cardiac output. As far as their ability to stimulate the anterior pituitary-adrenal cortical mechanism, measured by the decrease in total circulating eosinophils, these hormones are again strikingly dissimilar. Epinephrine acts as a potent eosinopenic agent, whereas nor-epinephrine is devoid of any significant effect. This is in agreement with Thorn's statement which was published subsequent to the inception of this study (3).

The exact role that the hypothalamus plays in the anterior pituitary-adrenal cortical response to stress has not been fully elucidated. Recently, it has been demonstrated in rats that the hypothalamo-hypophyseal neural and vascular connections are not necessary for the stimulation of the anterior pituitary-adrenal cortical axis in response to stress $(20,21)$. This evidence was thought by Fortier and Selye (21) to eliminate the diencephalic centers as a necessary link in this chain of events. They state, "This seems to exclude these centers as the necessary activators of the hypophyseal corticotrophic function and lends indirect support to the humoral theory."

However, Hume (22) has shown that electrolytic lesions in the anterior hypothalamus prevent the usual anterior pituitary-adrenal cortical stimu- 
lation which follows stress, and that extracts of hypothalamic tissue are capable of stimulating ACTH production in animals rendered unresponsive by these lesions. This suggests that anterior hypothalamic centers secrete a neurohumor following stress and epinephrine administration which increases production of $\mathrm{ACTH}$ resulting in augmented output of 11,17 -oxysteroids by the adrenal cortex (3).

\section{SUMMARY AND CONCLUSIONS}

The eosinopenic effects of U. S. P. epinephrine, synthetic L-epinephrine, and nor-epinephrine were compared in 15 normal subjects. Another pharmacological difference between the adrenal medullary hormones has been demonstrated. The eosinopenic effect of U. S. P. epinephrine depends on its L-epinephrine content and not on the norepinephrine present. Epinephrine is the anterior pituitary-adrenal cortical stimulant, whereas its non-methylated analogue, nor-epinephrine, is devoid of effect.

\section{BIBLIOGRAPHY}

1. Hench, P. S., Kendall, E. C., Slocumb, C. H., and Polley, H. F., The effect of a hormone of the adrenal cortex (17 hydroxy-11-dehydrocorticosterone: Compound $\mathrm{E}$ ) and of pituitary adrenocorticotrophic hormone on rheumatoid arthritis. Proc. Staff Meet., Mayo Clin., 1949, 24, 181.

2. Hench, P. S., Slocumb, C. H., Barnes, A. R., Smith, H. L., Polley, H. F., and Kendall, E. C., The effects of the adrenal cortical hormone 17-hydroxy11-dehydrocorticosterone (Compound E) on the acute phase of rheumatic fever. Proc. Staff Meet., Mayo Clin., 1949, 24, 277.

3. Thorn, G. W., Bayles, T. B., Massell, B. F., Forsham, P. H., Hill, S. R., Jr., Smith, S., and Warren, J. E., Studies on the relation of pituitaryadrenal function to rheumatic disease. New England J. Med., 1949, 241, 529.

4. Long, C. N. H., The conditions associated with the secretion of the adrenal cortex. Federation Proc., 1947, 6, 461.

5. Hills, A. G., Forsham, P. H., and Finch, C. A., Changes in circulating leukocytes induced by the administration of pituitary adrenocorticotrophic hormone (ACTH) in man. Blood, 1948, 3, 755.
6. Forsham, P. H., Thorn, G. W., Prunty, F. T. G., and Hills, A. G., Clinical studies with pituitary adrenocorticotrophin. J. Clin. Endocrin., 1948, 8, 15.

7. Goldenberg, M., Faber, M., Alston, E. J., and Chargaff, E. C., Evidence for the occurrence of nor-epinephrine in the adrenal medulla. Science, 1949, 109, 534.

8. Tullar, B. F., The separation of L-arterenol from natural U. S. P. epinephrine. Science, 1949, 109, 536.

9. Auerbach, M. E., and Angell, E., The determination of arterenol in epinephrine. Science, 1949, 109, 537.

10. Thorn, G. W., Forsham, P. H., Prunty, F. T. G., and Hills, A. G., A test for adrenal cortical insufficiency. J.A.M.A., 1948, 137, 1005.

11. Tobian, L., Personal communication.

12. Randolph, T. G., Blood studies in allergy. I. Direct counting chamber determination of eosinophils by propylene glycol aqueous stains. J. Allergy, 1944, 15, 89.

13. Discombe, G., Criteria of eosinophilia. Lancet, 1946, $1,195$.

14. de Leeuw, N. K. M., and Blaustein, A., Studies of blood passed through an artificial kidney. Blood, 1949, 4, 653.

15. Jorpes, J. E., Heparin in the Treatment of Thrombosis. Oxford University Press, London, 1946.

16. Henneman, P. H., Wexler, H., and Westenhaver, M. M., A comparison of eosin-acetone and phloxine-propylene glycol diluents in eosinophil counts. J. Lab. \& Clin. Med., 1949, 34, 1017.

17. Goldenberg, M., Pines, K. L., Baldwin, E. DeF., Green, D. G., and Roh, C. E., The hemodynamic response of man to nor-epinephrine and epinephrine and its relation to the problem of hypertension. Am. J. Med., 1948, 5, 792.

18. Luduena, F. P., Ananenko, E., Siegmund, O. H., and Miller, L. C., Comparative pharmacology of the optical isomers of arterenol. J. Pharmacol. \& Exper. Therap., 1949, 95, 155.

19. Tainter, M. L., Tullar, B. F., and Luduena, F. P., Levo-arterenol. Science, 1948, 107, 39.

20. Cheng, C. P., Sayers, G., Goodman, L. S., and Swinyard, C. A., Discharge of adrenocorticotrophic hormone from transplanted pituitary tissue. Am. J. Physiol., 1949, 159, 426.

21. Fortier, C., and Selye, H., Adrenocorticotrophic effect of stress after severance of hypothalamohypophyseal pathways. Am. J. Physiol., 1949, 159, 433.

22. Hume, D. M., The role of the hypothalamus in the pituitary-adrenal cortical response to stress. J. Clin. Invest., 1949, 28, 790. 